This item was submitted to Loughborough's Research Repository by the author.

Items in Figshare are protected by copyright, with all rights reserved, unless otherwise indicated.

\title{
Metrology of silicon photovoltaic cells using coherence correlation interferometry
}

PLEASE CITE THE PUBLISHED VERSION

http://dx.doi.org/10.1109/PVSC.2011.6186670

PUBLISHER

(C) IEEE

VERSION

AM (Accepted Manuscript)

LICENCE

CC BY-NC-ND 4.0

\section{REPOSITORY RECORD}

Maniscalco, Bianca, Piotr M. Kaminski, M. Conroy, D. Mansfield, Y. Yu, Kevin Bass, Gianfranco Claudio, and Michael Walls. 2019. "Metrology of Silicon Photovoltaic Cells Using Coherence Correlation Interferometry". figshare. https://hdl.handle.net/2134/14666. 
This item was submitted to Loughborough's Institutional Repository (https://dspace.lboro.ac.uk/) by the author and is made available under the following Creative Commons Licence conditions.

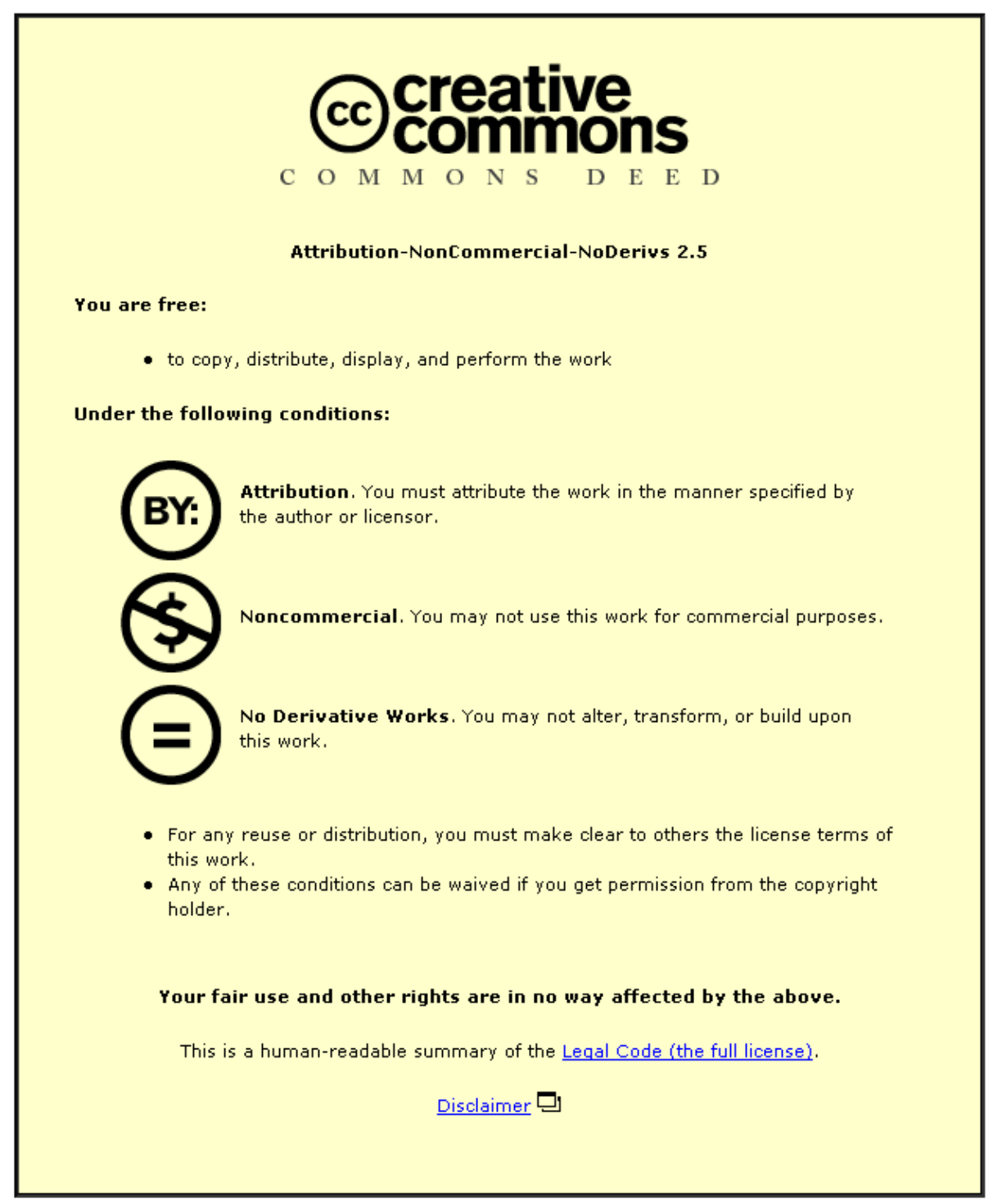

For the full text of this licence, please go to: http://creativecommons.org/licenses/by-nc-nd/2.5/ 


\title{
METROLOGY OF SILICON PHOTOVOLTAIC CELLS USING COHERENCE CORRELATION INTERFEROMETRY
}

\author{
B Maniscalco ${ }^{1}$, P M.Kaminski ${ }^{1}$, M Conroy $^{2}$, D Mansfield $^{2}, \mathrm{Y} \mathrm{Yu}^{2}$ \\ $\mathrm{K}_{\text {Bass }}{ }^{1}$, G Claudio ${ }^{1}$ and $\mathrm{J}$ M Walls ${ }^{1}$ \\ ${ }^{1}$ CREST, Department of Electronic and Electrical Engineering, Loughborough University, Loughborough, Leicestershire, LE11 3TU, \\ UK \\ ${ }^{2}$ Ametek Taylor Hobson, PO Box 36, 2 New Star Road, Leicester, LE4 9JG, UK
}

\begin{abstract}
Surface metrology plays an important role in the development and manufacture of photovoltaic cells and modules. Coherence Correlation Interferometry $(\mathrm{CCl})$ is a non-contacting surface metrology tool with potentially important applications in the characterization of photovoltaic devices. Its major advantages are that it is fast, non-destructive and it takes its data from a relatively large and hence representative area. A special mode, called "stitching $x-y$ " can be used to provide information on a wider area, combining measurements taken in different zones of the sample. The technique is capable of providing surface roughness and step height measurements with sub-nanometre precision. It is also capable of measuring quantitatively surface texture and surface form in three dimensions and it now has a new capability to measure thin film and thick film thickness. $\mathrm{CCl}$ measurements are presented on a range of features on silicon photovoltaic cells including surface roughness, surface texture, the profile of laser grooves for buried contacts as well as the roughness and thickness of silicon nitride thin films. Complementary analysis using spectroscopic ellipsometry is also presented for verification. $\mathrm{CCl}$ is a sensitive, non-destructive metrology technique with potential use as an in-line quality assurance tool in the large scale production of photovoltaic modules.
\end{abstract}

\section{INTRODUCTION}

The quality of surfaces and thin films is important to the performance of all photovoltaic devices including crystalline and polycrystalline silicon, thin film photovoltaics (CdTe, CIGS and amorphous silicon) as well as to third generation technologies such as dye-sensitized and organic photovoltaics. A number of tools are used to measure properties such as surface roughness, texture, thin film thickness and profiles of laser ablated surfaces, and these include stylus profilometry, spectroscopic ellipsometry, Atomic Force Microscopy (AFM) and Scanning Electron Microscopy (SEM). Coherence Correlation Interferometry (CCl) is a white light interferometry technique which is a non-contacting surface metrology tool. It extracts data rapidly from a large and hence representative area from 165 um x 165 um using a $100 x$ objective lens to $6.6 \mathrm{~mm} \times 6.6 \mathrm{~mm}$ for a $2.5 \mathrm{x}$ objective lens. The technique is fast and provides a three- dimensional image of the surface together with analysis that includes root mean square roughness $(\mathrm{Sq})$, maximum peak height (St), step height and surface profile measurements. Recently, thin film and thick film thickness measurements for transparent films have been added.

The collection of rapid metrology data using the $\mathrm{CCl}$ technique enables fast process optimization and quality assurance.

\section{Coherence Correlation Interferometry (CCI)}

Coherence Correlation Interferometry $(\mathrm{CCl})$ [1] is a scanning white light interferometry (SWLI) technique. The $\mathrm{CCl}$ combines a coherence correlation algorithm with a high-resolution digital camera array to generate a threedimensional representation of a structure by scanning the fringes through the surface and then processing the information to transform the data into a quantitative threedimensional image with $0.01 \mathrm{~nm}$ vertical resolution. The data can then be used to generate accurate quantitative parameters such as Root Mean Square (RMS) roughness. Recently, the technique has been extended to measurements of thin film thickness from semi-transparent thin films.

The advantages of $\mathrm{CCl}$ over other metrology techniques are that it is fast, non-contacting, (and hence nondestructive) and it takes its data from a relatively large and hence more representative area. The lateral resolution is $\sim 0.5 \mathrm{um}$ and is determined by the wavelength of light and the NA of the objective lens.

\section{EXPERIMENTAL}

\section{Surface roughness}

The characterisation of surface finish is important in the development of photovoltaic cell technology as well as in the quality control in module manufacturing. The $\mathrm{CCl}$ tool used in this study was the $\mathrm{CCl}$ Sunstar (Ametek Taylor Hobson) This tool creates topographical images from which it is possible to extract information on surface roughness. $\mathrm{CCl}$ allows accurate measurement of surface finish to be obtained in few minutes. Examples of surface finish measurements are shown in Figure 1 and Figure 2. Figure 1(a) shows a two dimensional image of a surface of polished crystalline silicon while Figure 1(b) shows a three-dimensional image created using "TalyMap", a software package provided with the $\mathrm{CCl}$ Sunstar. 


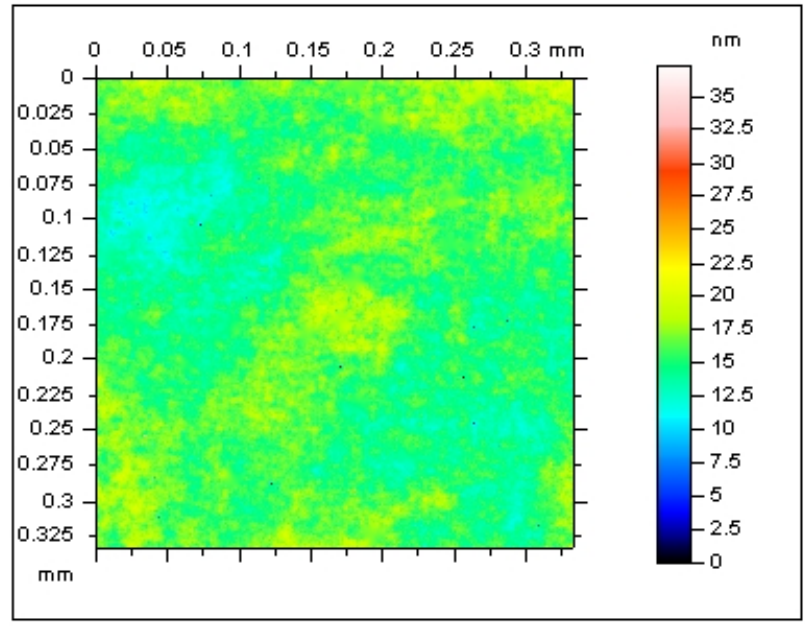

Figure 1(a). Two-dimensional topographical $\mathrm{CCl}$ image of a polished silicon surface.

The polished silicon surface is very smooth. The RMS roughness $(\mathrm{Sq})$ is measured at $1.579 \mathrm{~nm}$ across the $325 \mu \mathrm{m} \times 325 \mu \mathrm{m}$ measurement area. The maximum height disparity (St) across this area is $37.29 \mathrm{~nm}$. These results are shown in figure 1(b), which represent three dimensional imaging of polished surface, with correlated surface Sq and St values.

The two-dimensional image can be considered as the "raw data", which is extracted directly from the measurement. After few imagine processing steps, such as leveling and thresholding processes, the data can be transformed in three-dimensional image. This type of imaging allows a clearer visualization of the surface. $\mathrm{CCl}$ software recreates the surface morphology from the optical measurements, underlining possible defects or anomalisms in the sample.

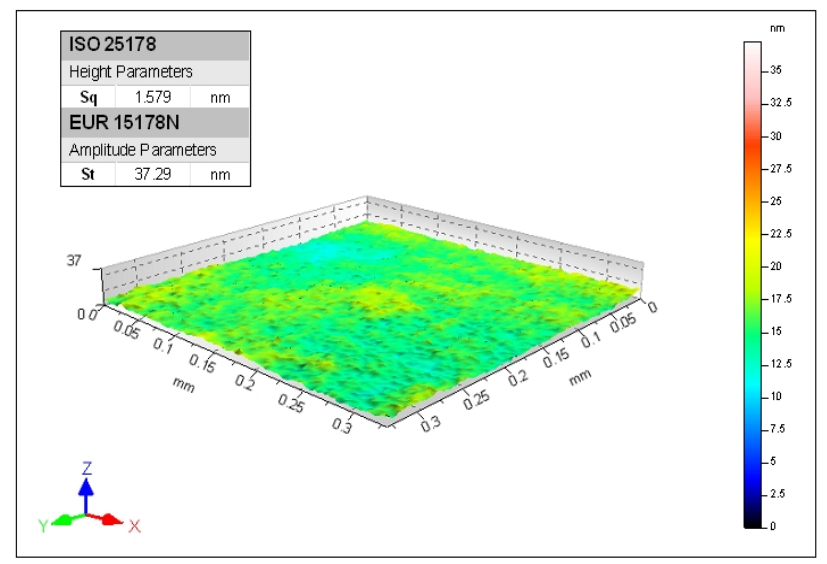

Figure 1 (b) $\mathrm{CCl}$ image of a polished silicon surface with RMS roughness $1.579 \mathrm{~nm}$.

The three-dimensional imaging is important to better understand the surface roughness value Sq, correlated to the sample morphology. It is very effective, especially for what concerns more complex topographies, such as etching or laser grooves ablated on the surface.

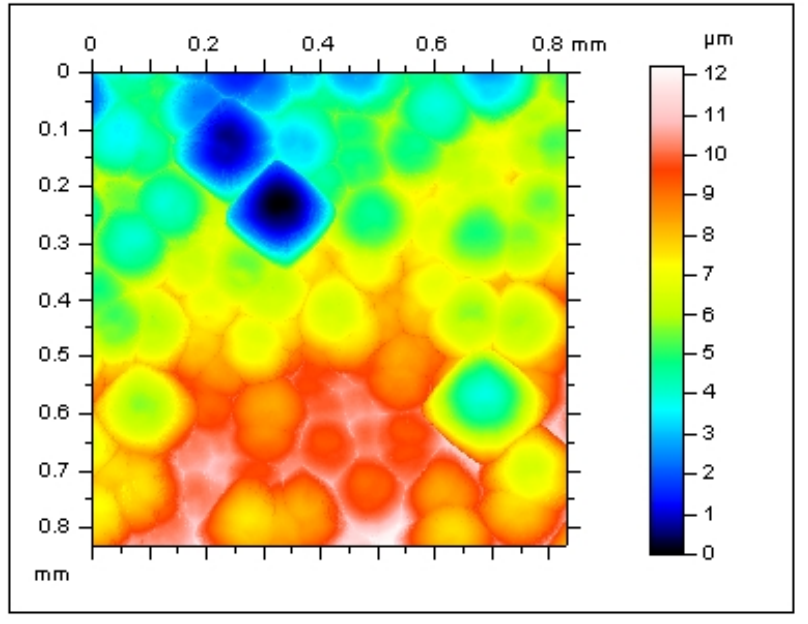

Figure 2(a). $\mathrm{CCl}$ image of an alkaline etched silicon surface.

Figure 2 (a) shows a two dimensional image of an etched crystalline silicon surface showing the early development of pyramid texture. The surface was lightly etched using sodium hydroxide. The etching process has a dramatic effect on the surface texture. It is carried out at $90^{\circ} \mathrm{C}$, for about five minutes. Figure 2(b) shows its threedimensional equivalent. The RMS roughness measured on this surface is $2.332 \mu \mathrm{m}$ and the maximum height disparity (St) across same area is $12.21 \mu \mathrm{m}$.

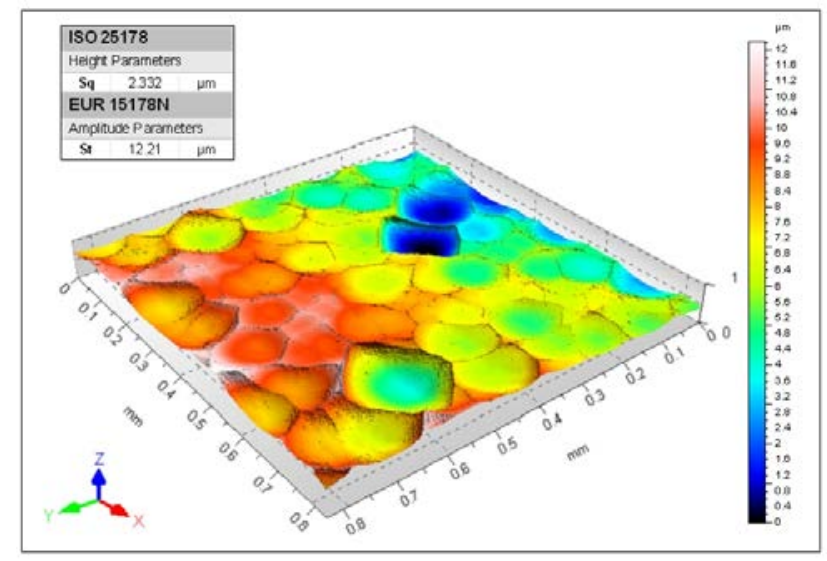

Figure 2(b). $\mathrm{CCl}$ image of an alkaline etched silicon surface with RMS surface roughness of $2.332 \mu \mathrm{m}$.

These analyses can be made quickly and the tool is suitable for use in quality control in a manufacturing environment.

\section{Laser ablated grooves}

Solar cells need to be electrically connected. There are different methods in order to create efficient electrical contacts. Screen printing is commercially the most popular technique for silicon solar cells. However, although the processes used to create Laser Groove 
Buried Contacts (LGBC) $[2,3]$ are now considered too expensive for flat panel modules, they have advantages in applications where small, high efficiency cells are required for medium concentrating photovoltaics (CPV). Laser ablation is used to create the buried contacts for these small silicon solar cells [4]. It is important to characterize the width, depth, uniformity and consistency of the grooves

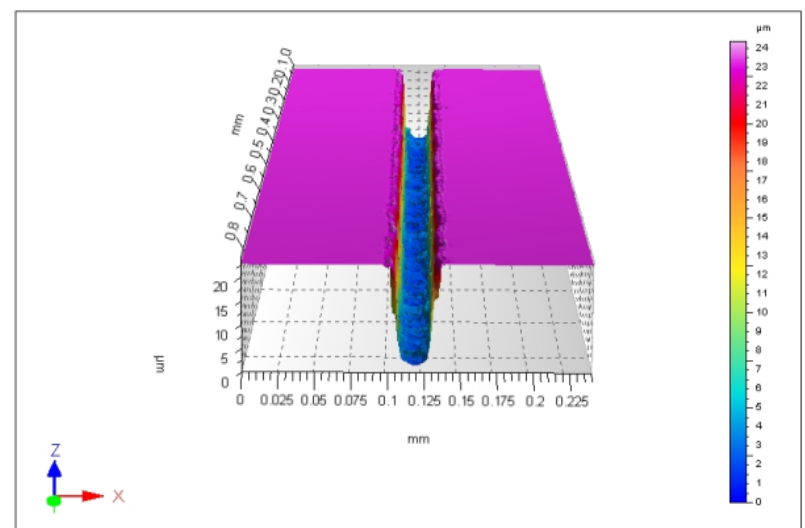

Figure 3(a) Three dimensional $\mathrm{CCl}$ image of a laser ablated groove for LGBC in silicon (Nd:YAG laser, $3.5 \mathrm{~kW})$.

Figure $3(\mathrm{a})$ is a three-dimensional $\mathrm{CCl}$ image of a laser ablated trench in polished silicon, using a Nd:YAG laser (wavelength $=1064 \mathrm{~nm}$ ) at a power of $3.5 \mathrm{~kW}$. Figure $3(\mathrm{~b})$ below shows a quantitative cross-sectional analysis taken across this image to provide accurate measurements of groove width and depth together with information on trench shape. The $\mathrm{CCl}$ image provides a rapid three dimensional and quantitative analysis of the laser trenches. Cross-sections at any position on the groove can be analysed in detail once the data has been accumulated.

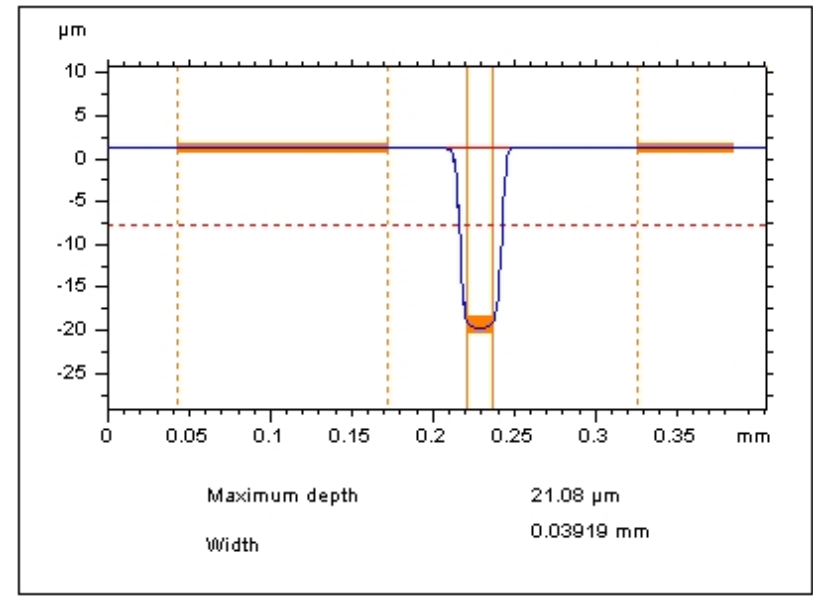

Figure 3(b). The two dimensional mean cross -section of the laser groove of figure 5 , revealing a depth of $21.08 \mu \mathrm{m}$ and a width of $39.19 \mu \mathrm{m}$.
Groove depth and width is controlled primarily using laser power. Table 1 provides the average depth and width of the grooves created on crystalline silicon coated with a silicon nitride anti-reflective layer, using $\mathrm{Nd}$ :YAG laser at different powers in the range $2 \mathrm{~kW}$ to $4.3 \mathrm{~kW}$, maintaining the other parameters constant. At $2 \mathrm{~kW}$ the laser had insufficient power to ablate a groove. Thereafter, both groove width and depth increased with increasing power.

\begin{tabular}{|c|c|c|}
\hline $\begin{array}{c}\text { Power } \\
(\mathrm{kW})\end{array}$ & $\begin{array}{c}\text { Depth } \\
(\mu \mathrm{m})\end{array}$ & $\begin{array}{c}\text { Width } \\
(\mu \mathrm{m})\end{array}$ \\
\hline 4.3 & 24.33 & 54.83 \\
\hline 4 & 22.12 & 47.49 \\
\hline 3.5 & 18.47 & 43.09 \\
\hline 3 & 12.93 & 40.15 \\
\hline 2.5 & 5.07 & 33.79 \\
\hline 2 & - & \\
\hline
\end{tabular}

Table 1. Groove depth and width values for different laser powers.

Characterization of the ablated grooves and their subsequent processing and efficiency measurement allows the grooves in the LGBC cells to be optimized. $\mathrm{CCl}$ can play a useful role providing accurate characterization of each trench and providing rapid measurements of surface topography. The $\mathrm{CCl}$ provides accurate measurement for depth, width and shape of the grooves.

Laser ablation has an important role in the interconnection process of solar cells. The electrical characteristics of the device depend on the laser scribing process, which controls the efficiency of the cell. The patterning process depends on different parameters, which can be both linked to the laser characteristics (wavelength, power, frequency...) and to the motion system (system height, scribing speed applied...).

\section{Thin and thick film thickness measurements}

The capability of the $\mathrm{CCl}$ has been extended recently to the measurement of semi-transparent thin and thick film thickness using a new algorithm. Film thickness is an important parameter in all photovoltaic technologies.

$\mathrm{CCl}$ can be used to measure the thickness of semitransparent films. There are two different analyses depending on whether measurements are made on thick or thin films. Films are considered as 'thick films' for physical thickness values higher than $1-2 \mu$ m (depending on the refractive index and NA). In order to obtain an 
accurate measurement, it is necessary to provide the refractive index of the material, which is either assumed to be the bulk value or better measured directly using another technique such as using other instruments, such as spectroscopic ellipsometry. As result of SWLI interaction with the film, two localised fringe bunches appear on the scanned surface, each corresponding to a surface interference. $\mathrm{CCl}$ provide accurate thick film thickness measurements, which are relatively straightforward to be determined locating the position of the two envelope maxima. "Pattern" measurement can be used to obtain data from different points on the sample surface to obtain information on thickness uniformity of the deposited film.

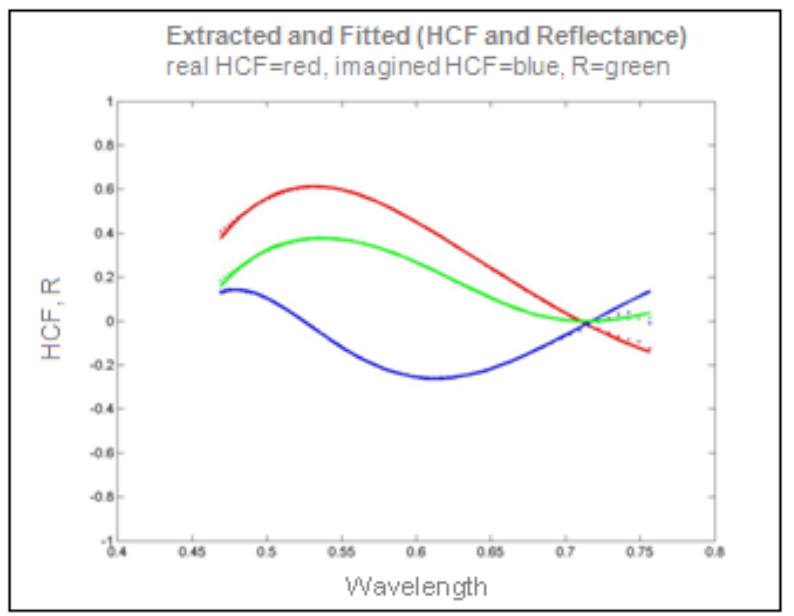

Figure 4. Extracted \& fitted HCF and Reflectance of $278 \mathrm{~nm}$ thickness of $\mathrm{Si}_{3} \mathrm{~N}_{4}$ coating on polished $\mathrm{Si}$, which show a good fitting of the function (continuous line) over the measured data (dotted line).

For thinner films, the SWLI interaction leads to the formation of a single interference maximum. In this regime, a new approach has to be employed termed the 'helical complex field' (HCF) approach $[5,6]$, originally designed to determine thin film thickness, from $1 \mu \mathrm{m}$ down to $25 \mathrm{~nm}$. The HCF function is defined as the product of the net field reflectance of a known 'reference' material with the ratio of the +ve arm sidebands of the Fourier transforms of the interference intensities of the film and 'reference' samples. It may be shown to equate to a topographically defined helix modulated by the electrical field reflectance of the film. As such, it provides a 'signature' of the thin film structure (currently restricted to a single layer) so that through optimisation, the thin film structure may be determined on a local scale $(1.25 \mu \mathrm{m})$ [6]. In order to use the HCF function approach, it is necessary to provide an a priori knowledge of the dispersive film index, which can be either assumed or measured. The "pattern" measurement can be performed also in thin film for an accurate characterization of thickness uniformity.

An accurate measurement of thin film thickness is relevant to PV application. In silicon cells technology, anti-reflection coatings play an important role to improve the light trapping and efficiency of silicon solar cells. Silicon nitride thin film coatings represent the most common passivation technique used in silicon PV [7] and they can be easily characterized using $\mathrm{CCl}$ technique. The technique provides both thin film thickness and surface roughness parameters from the same measurement data.

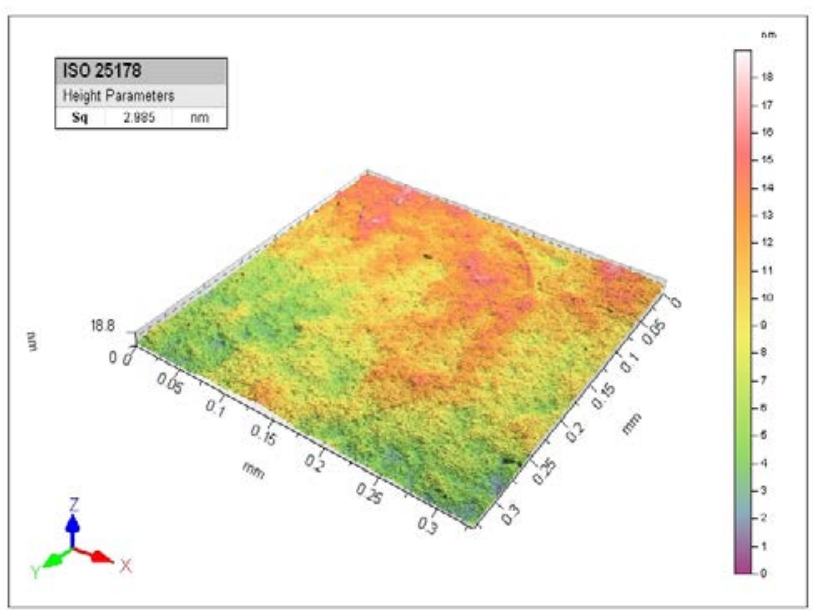

Figure 5. A CCl image of a silicon nitride layer on polished silicon (thickness $164.9 \mathrm{~nm}$, RMS roughness $\mathrm{Sq}=2.985 \mathrm{~nm}$ ).

The thickness of a silicon nitride layer is critical for its antireflective properties since a quarter wavelength is optimal. Figure 5 shows a $\mathrm{CCl}$ image of a silicon nitride antireflective layer deposited on polished silicon. Using refractive index $(n)$ and absorption $(k)$ dispersive values obtained directly using spectroscopic ellipsometry, the analysis reveals that the thickness of the Silicon Nitride film is $164.9 \mathrm{~nm}$ with surface RMS roughness of $2.985 \mathrm{~nm}$. This analysis shows the power of the technique allowing both thin film thickness and accurate surface roughness measurements to be obtained from a single analysis.

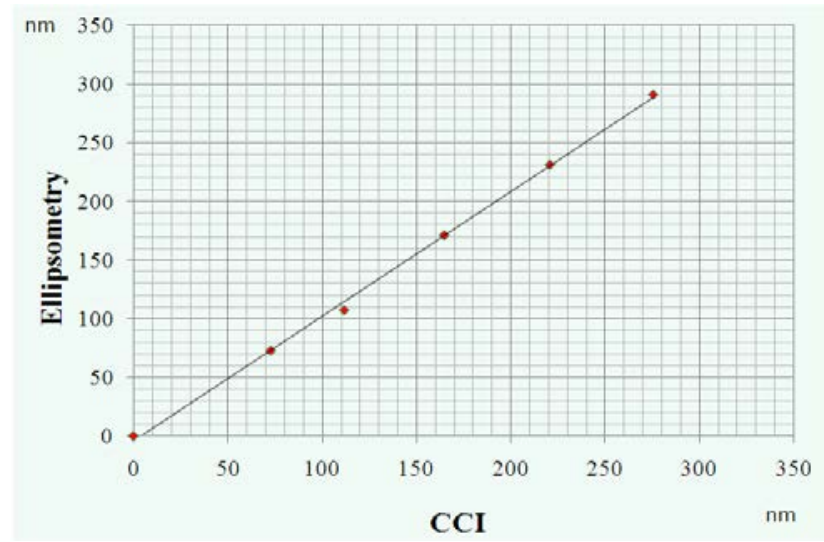

Figure 8. Correlation between $\mathrm{CCl}$ and Ellipsometry thickness measurements of Silicon Nitride thin films on silicon.

Thin film thickness measurement is a recent development of the $\mathrm{CCl}$ technique. As part of this study, the accuracy of 
the film thickness measurement was tested by correlating the results obtained from the same samples using ellipsometry (Horiba, Jobin Yvon, UVISEL). A series of uniform silicon nitride thin films of different thickness in the range $75 \mathrm{~nm}$ to $300 \mathrm{~nm}$ were prepared using sputtering. The silicon nitride films were deposited on to polished silicon. The ellipsometry data was obtained by taking the average from five different mapped points on the surface. A similar approach was taken using the $\mathrm{CCl}$ Sunstar; figure 6 shows the correlation between the series of thickness measurements over the thickness range with only small deviation. The correlation between the $\mathrm{CCl}$ results and spectroscopic ellipsometry is excellent. Similar good correlation has been obtained for a series of thin film metal-oxide samples providing a high degree of confidence in the technique.

\section{CONCLUSIONS}

Metrology plays an important role in the development and quality assurance of all photovoltaic devices. The $\mathrm{CCl}$ technique provides a three dimensional surface analysis which has the advantage that it is non-contacting and thereby non-destructive. The vertical resolution of the technique is at the atomic scale. The lateral resolution is governed by the wavelength of light $(\sim 0.5 \mathrm{um})$ and the NA of the objective lens and this will limit its suitability for some applications. However, the data is collected from an area which is more much larger than that obtained from techniques such as AFM and hence the analysis will tend to be more representative. The $\mathrm{CCl}$ technique provides a rapid means of characterizing a number of important parameters including surface roughness, step height, surface form, surface texture and its capability has now been extended to include thin film thickness. It is ideally suited to the characterization and measurement of laser ablated grooves.

\section{REFERENCES}

[1] A Bankhead and I McDonnell, "Interferometric Surface Profiling", GB2390676, 2004

[2] SR Wenham and MA Green, Australian Patent 570309, 1993

[3] NB Mason et al., Proc. 10th European Photovoltaic Solar Energy Conference, Lisbon 1991, 280

[4] S R Wenham, C B Honsberg and M A Green, "Buried Contact Silicon Solar Cells", Solar Energy Materials and Solar Cells 34, 101-110, 1994

[5] D Mansfield, "Extraction of film interface surfaces from scanning white light Interferometry", Proc. SPIE vol. 7101, 2008

[6] D Mansfield, "The distorted helix: thin film extraction from scanning white light interferometry", Proc. SPIE vol.6186, 2006
[7] Martin A Green, Jianhua Zhao, Aihua Wang and Stuart R Wenham, "Very High Efficiency Silicon Solar CellsScience and Technology", IEEE transactions on electron devices, vol. 46, no. 10, October 1999 